\title{
Faktor-Faktor yang Mempengaruhi Minat Menggunakan E-Zakat dalam Membayar Zakat, Infaq, dan Sedekah
}

\author{
Puguh Kharisma*, Prabowo Yudo Jayanto \\ Jurusan Akuntansi, Fakultas Ekonomi, Universitas Negeri Semarang \\ *Email: puguhkharisma.pk@gmail.com
}

\begin{abstract}
In the modern era like today, it also changes the model of financial transactions that were previously carried out conventionally, now it can be done digitally or online using financial technology. This digital transaction trend has also changed the payment methods for Zakat, Infaq, and Alms that were previously done conventionally, now it can be done digitally through the E-Zakat service provided by the Zakat Management Organization. In the last 5 years, there has been a significant trend of increasing digital payments of Zakat, Infaq, and Almsgiving. This has become a new phenomenon in collecting Zakat, Infaq, and Alms funds so that what factors also influence the interest of muzaki to use E-Zakat in paying Zakat, Infaq, and Alms so that there is a trend of increasing the intensity of digital ZIS payments needs to be known so that the collection Zakat, Infaq and Alms funds can be maximized. The population of this research is amil who work at OPZ at provincial and national scale in Semarang City who have opened E-Zakat service. The sampling technique used was quota sampling and the number of samples was 70 respondents. Primary data collection using a questionnaire method. Data were analyzed using descriptive analysis and Structural Equation Modeling (SEM) with the SmartPLS 3.0 analysis tool. The results show that Usability and Transparency have a significant positive effect, Risk has a significant negative effect on Interests in Using E-Zakat, but Accountability has no significant effect on Interests in Using E-Zakat in Paying Zakat, Infaq, and Alms. Based on the research results, it can be concluded that the interest in using E-Zakat in paying Zakat, Infaq, and Alms is influenced by the Usability, Risk and Transparency variables of the E-Zakat service. The suggestions from researchers for $O P Z$ are expected to be able to maintain and improve the quality of service and add features for muzaki / donors. For further researchers, it is hoped that they can develop research by examining other factors that are thought to influence the interest in using E-Zakat in paying Zakat, Infaq, and Alms. It is expected to present the ease of use variable to complement the variable elements in the Technology Acceptance Model (TAM) theory.
\end{abstract}

\section{Keywords: E-Zakat, Zakat Management Organization, Management, Digital Transactions, ZIS, Online}

\begin{abstract}
Abstrak
Pada era modern seperti saat ini, turut mengubah model transaksi keuangan yang tadinya dilakukan secara konvensional, saat ini dapat dilakukan secara digital atau online menggunakan financial technology. Tren transaksi digital ini juga turut mengubah metode pembayaran Zakat, Infaq, dan Sedekah yang tadinya dilakukan secara konvensional, saat ini dapat dilakukan secara digital melalui layanan E-Zakat yang disediakan oleh Organisasi Pengelola Zakat. Dalam kurun waktu 5 tahun terakhir, telah terjadi tren peningkatan pembayaran Zakat, Infaq, dan Sedekah secara digital yang cukup signifikan. Hal ini menjadi fenomena baru dalam penghimpunan dana Zakat, Infaq, dan Sedekah sehingga faktor-faktor apa saja yang turut mempengaruhi minat muzaki menggunaakan E-Zakat dalam membayar Zakat, Infaq, dan Sedekah sehingga terjadi tren peningkatan instensitas pembayaran ZIS secara digital perlu diketahui agar penghimpunan dana Zakat, Infaq, dan Sedekah dapat maksimal. Populasi penelitian ini adalah amil yang bekerja pada OPZ berskala Provinsi dan Nasional di Kota Semarang yang telah membuka layanan E-Zakat. Teknik pengambilan sampel penelitian menggunakan teknik quota sampling dan jumlah sampel sebanyak 70 responden. Pengumpulan data primer menggunakan metode kuesioner. Data dianalisis menggunakan analisis deskriptif dan Structural Equation Modeling (SEM) dengan alat analisis SmartPLS 3.0. Hasil penelitian menunjukkan bahwa Kegunaan dan Transparansi berpengaruh positif signifikan, Risiko berpengaruh negatif signifikan terhadap Minat Menggunakan E-Zakat, namun Akuntabilitas tidak berpengaruh siginifkan terhadap Minat Menggunakan E-Zakat dalam Membayar Zakat, Infaq, dan Sedekah Berdasarkan
\end{abstract}


hasil penelitian, maka dapat disimpulkan bahwa minat menggunakan E-Zakat dalam membayar Zakat, Infaq, dan Sedekah dipengaruhi oleh variabel Kegunaan, Risiko dan Transparansi dari layanan E-Zakat. Saran dari peneliti untuk OPZ diharapkan untuk dapat mempertahankan dan meningkatkan kualitas pelayanan serta menambah fitur-fitur bagi muzaki/donatur. Bagi peneliti selanjutnya diharapkan dapat mengembangkan penelitian dengan meneliti faktor-faktor lain yang diperkirakan dapat mempengaruhi minat menggunakan E-Zakat dalam membayar Zakat, Infaq, dan Sedekah. Diharapkan menghadirkan variabel kemudahaan penggunaan untuk melengkapi unsur variabel dalam teori Technology Acceptance Model (TAM).

Kata Kunci: E-Zakat, Organisasi Pengelola Zakat, Pengelolaan, Transaksi digital, ZIS, Online.

\section{PENDAHULUAN}

Dalam era modern seperti saat ini, perkembangan teknologi mulai dari terciptanya teknologi baru atau inovasi dari teknologi sebelumnya berlangsung begitu cepat sebagai jawaban kebutuhan manusia akan teknologi untuk menunjang berbagai macam aktivitasnya. Salah satu bidang yang terdampak akibat dari perkembangan teknologi adalah digitalisasi transaksi keuangan. Pada saat ini muncul istilah uang elektronik (e-money) yaitu merupakan sebuah perpaduan antara sektor teknologi dan sektor keuangan.

Perkembangan teknologi digital bebar-benar telah merubah gaya hidup masyarakat pada era saat ini yang sangat dekat dengan gadget dan internet. Asosiasi Penyelenggara Jasa Internet (APJII) pada tahun 2017 menyatakan bahwa pengguna internet di Indonesia mencapai 196,7 juta jiwa atau sebesar $73,47 \%$ dari total penduduk Indonesia (267,7 juta) telah menggunakan dan mengakses internet. Di lansir dari berita Kompas, Bank Indonesia menyebutkan bahwa telah terjadi peningkatan yang sangat signifikan dalam transaksi menggunakan uang digital pada kuartal IV tahun 2019 meningkat sebesar 241,2 persen. Selanjutnya adalah gerakan penggalakan transaksi keuangan non tunai dengan menggunakan e-money yang telah dikampanyekan oleh Bank Indonesia untuk meningkatkan perekonomian.

Akhir ini penggunaan transaksi pembayaran melalui e-money meningkat, Selain dengan adanya dukungan dari pemerintah (Bank Indonesia), peningkatan transaksi melalui e-money dipicu oleh banyaknya keuntungan yang diberikan oleh e-money, baik masyarakat, industri, maupun bagi bank Indonesia. Beberapa keuntungan dalam menggunakan e-money adalah, pertama, memberikan kemudahan dalam transaksi pembayaran secara cepat dan aman bagi masyarakat luas. Kedua, masalah cash handling dapat dipecahkan yang selama ini sering dialami ketika menggunakan uang tunai sebagai pembayaran bagi industri. Ketiga, meningkatkan efisiensi percetakan uang dan penggandaan uang bagi bank Indonesia. Tidak heran jika e-money telah banyak digunakan oleh masyarakat. Beberapa transaksi yang sering digunakan bahkan diharuskan dengan e-money adalah parkir, transportasi ( $m r t, \mathrm{krl}$, lrt, serta transjakarta), tol. Bahkan uang elektronik sudah menjalar ke berbagai instansi seperti pendidikan. Di dunia pendidikan aplikasi e-money biasanya dalam bentuk kartu mahasiswa, atau kartu khusus yang dapat digunakan dalam transaksi di wilayah institusi terkait (Utami and Kusumawati 2017).

Selain aktivitas yang terdampak oleh digitalisasi transaksi keuangan oleh masyarakat yang telah disebutkan sebelumnya, transaksi digital juga mulai diadaptasi oleh Organisasi Pengelola Zakat (OPZ) dengan membuka layanan zakat secara digital atau online melalui E-Zakat untuk memfasilitasi pembayaran Zakat, Infaq, dan Sedekah (ZIS) secara digital dengan menggunakan $e$ money. Jika pada umumnya muzaki membayar zakat dengan cara manual mendatangi langsung ke kantor OPZ dengan menggunakan uang tunai, saat ini muzaki dapat membayar zakat secara online melalui payroll, e-payment, e-commerce, dan crowdfunding. Dalam kurun waktu 4 tahun terakhir terhitung sejak 2016, telah terjadi peningkan yang cukup signifikan terhadap penghimpunan ZIS secara digital. Pada tahun 2016, sebesar 1\% penerimaan ZIS secara digital dari keseluruhan, kemudian pada tahun 2019, persentase penerimaan ZIS secara digital mencapai $14 \%$ dan pada pertengahan 2020 mencapai $20 \%$. Hal ini cukup menegaskan bahwa selain jumlah dana ZIS yang dihimpun terus meningkat, terdapat fenomena perubahan cara pembayaran ZIS yang ditempuh oleh muzaki atau donatur dalam membayar ZIS. 
Dikutip dari website Baznas, sejak tahun 2016 Baznas telah memberi perhatian khusus terhadap penghimpunan ZIS secara online melalui platform digital. Baznas juga telah memberi penegasan tentang kehalalan metode pembayaran ZIS secara digital hukumnya adalah sah. Penggunaan e-money sebagai alat transaksi itu diperbolehkan dengan ketentuan mengikuti aturan yang terdapat dalam Fatwa DSN MUI No. 116/DSN-MUI/IX/2017 Tentang Uang Elektronik Syariah. E-money adalah sarana transaksi yang dapat memudahkan serta memberikan kenyamanan dalam kegiatan bertransaksi dengan efisien, karena masyarakat tidak perlu membawa uang dengan jumlah yang banyak, cukup membawa ponsel yang telah dilengkapi dengan aplikasi kita sudah bisa melakukan transaksi.

Fitur e-zakat akan menjadikan pembayaran ZIS dapat dilakukan dengan mudah oleh muzaki. Muzaki dapat membayar zakatnya dari mana saja dan dapat memilih lembaga apa yang akan dijadikan sebagai pemegang amanah untuk disalurkan kepada mustahik tanpa harus datang langsung ke kantor OPZ. Dengan demikian, akan meningkatkan intensitas muzaki untuk terus membayar ZIS. Semakin banyak muzaki yang tertarik menggunakan layanan ini, maka potensi penerimaan zakat juga akan meningkat. Penelitian yang dilakukan oleh Ozturk (2016) menemukan bahwa faktor kegunaan mempunyai pengaruh terhadap minat menggunakan cashless payment service. Namun hasil berbeda ditemukan dalam penelitian Ramadhan, dkk (2016) yang menemukan bahwa faktor kegunaan tidak berpengaruh terhadap minat menggunakan $e$-money.

Kemudian, layanan e-zakat ini dapat menunjukkan akuntabilitas dan transparansi OPZ terkait. Muzaki yang hendak membayarkan zakatnya menggunakan layanan e-zakat, dapat mengakses informasi tentang laporan keuangan OPZ dan pemberdayaan serta kemana dana tersebut didistribusikan. Semakin akuntabel dan transparan OPZ, maka kepercayaan muzaki akan semakin meningkat dan yakin untuk membayarkan zakatnya kepada OPZ sehingga hal ini dapat meningkatkan potensi penerimaan zakat. Menurut penelitian yang dilakukan oleh Rahayu, et al. (2018) menemukan bahwa akuntabilitas dan transparansi OPZ berpengaruh terhadap minat muzaki untuk membayarkan zakatnya. Serupa dengan penelitian yang dilakukan oleh Pangestu \& Jayanto (2017) bahwa akuntabilitas mempengaruhi motivasi muzaki dalam membayar zakat pada OPZ. Namun penelitian oleh Maulidiyah \& Darno (2019) menemukan bahwa transparansi tidak berpengaruh terhadap minat donatur dalam menyalurkan donasinya.

Paparan tentang phenomena gap \& research gap yang telah dikemukakan di atas akan menjadi latar belakang pengajuan penelitian ini. Dengan memperhatikan faktor-faktor yang mempengaruhi minat penggunaan $e$-money, penelitian ini akan menguji bagaimana pengaruh $e$ zakat terhadap pengelolaan Zakat, Infak, dan Sedekah (ZIS) oleh Lembaga Pengelola Zakat (LPZ). Penelitian ini betujuan untuk melihat pengaruh variabel kegunaan, risiko, akuntabilitas, dan transparansi yang terdapat dalam e-zakat terhadap pengelolaan Zakat, Infaq, dan Sedekah (ZIS) oleh Lembaga Pengelola Zakat (LPZ) di Kota Semarang. Orisinalitas dalam penelitian ini yaitu hadirnya faktor kegunaan, risiko, akuntabilitas, dan transparansi yang dihasilkan oleh sistem ezakat dan yang menjadi subjek penelitian ini ialah pegawai LPZ sebagai penyelenggara sistem tersebut yang membedakan dengan penelitian yang sudah ada yaitu dilihat dari sudut pandang muzaki/donatur.

\section{Technology Acceptance Model (TAM)}

Technology Acceptance Model (TAM) mampu menunjukkan bahwa minat individu dalam mengadopsi sebuah teknologi dipengaruhi beberapa hal dan salah satunya adalah kegunaan/manfaat dari penggunaan teknologi tersebut. Semakin tinggi manfaat/kegunaan yang dirasakan dari penggunaan sebuah teknologi, maka akan semakin meningkatkan motivasi individu untuk terus menggunakan teknologi tersebut untuk menunjang aktivitasnya. Implikasinya terhadap penelitian ini ialah semakin tinggi kegunaan/manfaat yang didapatkan muzaki/donatur dalam membayar ZIS melalui E-Zakat, maka akan semakin meningkatkan motivasi muzaki/donatur untuk terus membayar ZIS melalui E-Zakat. Hal ini dikuatkan dengan hasil penelitian yang dilakukan oleh Teoh et al. (2013) yang menemukan kegunaan/manfaat berpengaruh terhadap minat penggunaan mobile payment services dan Ozturk (2016) bahwa manfaat/kegunaan berpangaruh positif terhadap niat menggunaan cashless payment system.

\section{H1: Kegunaan Berpengaruh Positif dan Signifikan terhadap Minat Menggunakan E-Zakat}




\section{Innovation Difussion Theory (IDT)}

Innovation Difussion Theory (IDT), sebuah teori yang mampu mendasari bahwa risiko mampu mempengaruhi minat individu untuk mengadopsi sesuatu dalam aktivitasnya. Dalam konteks sistem informasi IDT pertama kali dikembangkan oleh Moore \& Benbasat (1991). Rogers (2003) berargumen bahwa individu yang berbeda mempunyai level yang berbeda-beda dalam keinginan mengadopsi produk atau layanan inovasi. Dia mengategorikan individu-individu (adopters) ini ke dalam 5 tingkatan berdasarkan orientasi nilai dan motif mereka dalam mengadopsi maupun menolak produk baru yaitu: laggards, late majority, early majority, early adopters, or innovators. Hubungan teori IDT dalam penelitian ini karena dalam IDT menjelaskan bahwa terdapat 5 kelompok adopter, salah satunya adalah early majority yaitu kelompok orangorang yang mengadopsi teknologi hanya ketika teknologi tersebut bermanfaat dan telah banyak diapdopsi pengguna lain. Dari sisi kesiapan menanggung risiko kelompok ini lebih berhati-hati. Maka dari itu persepsi risiko dapat mempengaruhi tingkat penggunaan teknologi baru seperti $e$ zakat. Semakin tinggi tingkat risiko pada E-zakat maka semakin rendah minat masyarakat untuk menggunakan $e$-zakat yang akan berimplikasi terhadap rendahnya pengelolaan ZIS oleh LPZ. Penelitian yang dilakukan oleh Fong (2016) menemukan bahwa risiko berpengaruh secara negatif signifikan terhadap niat menggunakan mobile payment system di Thailand dan Ozturk (2016) bahwa manfaat/kegunaan berpangaruh negatif terhadap niat menggunaan cashless payment system.

\section{H2: Risiko Berpengaruh Negatif dan Signifikan terhadap Minat Menggunakan E-Zakat}

\section{Good Corporate Governance (GCG)}

Good Corporate Governance (GCG) menurut Surya (2006:25) adalah pengambilan keputusan yang efektif yang ibangun melalui kultur organisasi, nilai-nilai, sistem, berbagai proses, kebijakan-kebijakan dan struktur organisasi yang bertujuan untuk mencapai bisnis yang menguntungkan, efisien, dan efektif dalam mengelola risiko dan bertanggungjawab dengan memperhatikan kepentingan stakeholder. Prinsip-prinsip yang terdapat dalam Good Corportae Governance (GCG) menurut Emirzon and Joni (2007:95) yaitu: (1) Keterbukaan (Transparancy), (2) Akuntabilitas (Accountability), (3) Pertanggungjawaban (Responsibility), (4) Independensi (Independency), dan (5) Kewajaran (Fairness). Adapun tujuan penerapan Good Corporate Governance (GCG) dalam entitas menurut Imam Syaputra (2002:9) adalah sebagai berikut: (1) mengakui dan melindungi hak dan kewajiban stakeholder, (2) meminimalisir agency cost, (3) mengurangi resiko, (4) memperbaiki etika dan pondasi perusahaan, (5) terciptanya kinerja entitas yang tinngi, (6) peningkatan kepuasan pelanggan.

Hubungan teori Good Corporate Governance (GCG) pada penelitian ini adalah bahwa akuntabilitas dan transparansi merupakan suatu unsur yang sangat penting dalam pertanggungjawaban entitas/perusahaan kepada selutuh stakeholder. Organisasi Pengelola Zakat (OPZ) sebagai sebuah entitas yang harus melakukan pertanggungjawaban kepada seluruh stakeholder dengan memperhatikan akuntabilitas dan transparansi organisasi. Melalui layanan ezakat, akuntabilitas dan transparansi perlu dihadirkan dalam E-Zakat agar muzaki/donator dan mustahik dapat memperoleh pertanggungjawaban dan akan meningkatkan keyakinan mereka. Semakin tinggi akuntabilitas dan transparansi yang dirasakan oleh muzaki, akan meningkatkan minat muzaki untuk membayar ZIS secara digital melalui E-Zakat. Sebaliknya, jika semakin rendah akuntabilitas dan transparansi dalam E-Zakat, maka akan semakin rendah minat menggunakan E-Zakat dalam membayar ZIS secara digital. Good Corporate Governance (GCG) ini mampu menunjukkan bahwa akuntabilitas menjadi faktor penting bagi muzaki. Pangestu \& Jayanto (2017) dalam penelitiannya menemukan bahwa akuntabilitas dan transparansi berpengaruh siginifikan terhadap motivasi muzaki membayar zakat.

\section{H3: Akuntabilitas Berpengaruh Positif dan Signifikan terhadap Minat Menggunakan E-Zakat} H4: Transparansi Berpengaruh Positif dan Signifikan terhadap Minat Menggunakan E-Zakat

\section{METODE PENELITIAN}

Penelitian ini termasuk kedalam jenis penelitian kuantitatif, yaitu penelitian yang digunakan oleh peneliti untuk meguji faktor-faktor apa saja yang mempengaruhi intensitas pembayaran ZIS secara digital. Penelitian ini menggunakan desain penelitian studi pengujian hipotesis (hypothesis testing study). Jenis data yang digunakan dalam penelitian ini adalah jenis 
data primer. Data primer dalam penelitian ini diperoleh langsung melalui instrumen kuesioner. Pengolahan data menggunakan metode analisis SEM dengan alat uji Smart PLS 3.0, untuk membuktikan hipotesis yang telah ditetapkan.

Pada umumnya, populasi dapat diartikan sebagai suatu himpunan atau sekumpulan elemen, unsur, atau unit dalam suatu kawasan atau ruang lingkup tertentu, yang memiliki atribut atau karakteristik tertentu, dan ditetapkan oleh peneliti sebagai objek analisis penelitian Wahyudin (2015). Populasi dalam penelitian ini adalah pegawai/Amil Organisasi Penglola Zakat (OPZ) yang telah membuka layanan E-Zakat di Kota Semarang yang berskala provinsi dan nasional. Teknik pengambilan sampel menggunakan teknik sampel kuota (quota sampling) Teknik sampling kuota diterapkan terlebih dahulu peneliti menentukan kuota jumlah atau ukuran sampel, baik untuk ukuran sampel keseluruhan maupun untuk ukuran pada bagian-bagiannya berdasarkan karakteristik tertentu. Dalam penelitian ini, peneliti menetapkan jumlah sampel sebanyak 70 responden. Sampel diambil dengan kriteria responden telah/pernah menggunakan layanan E-Zakat dalam membayar Zakat, Infaq, dan Sedekah (ZIS).

Tabel 1 Definisi Operasional Variabel

\begin{tabular}{|c|c|c|c|}
\hline Variabel & Definisi & Indikator & Sumber \\
\hline $\begin{array}{l}\text { Minat menggunakan } \\
\text { E-Zakat } \\
\text { (Y) }\end{array}$ & $\begin{array}{l}\text { Minat menggunakan } \\
\text { adalah keinginan atau } \\
\text { ketertarikan pada } \\
\text { suatu hal yang baik } \\
\text { benda maupun } \\
\text { aktivitas yang sesuai } \\
\text { dengan perasaaan } \\
\text { individu atau } \\
\text { seseorang tersebut } \\
\text { sebagai sumber } \\
\text { motivasi }\end{array}$ & $\begin{array}{ll}\text { - } & \text { Ketertarikan untuk } \\
\text { menggunakan } \\
\text { - } & \text { Bermaksud untuk } \\
\text { menggunakan } \\
\text { - } \\
\text { Berlanjut untuk } \\
\text { menggunakan di } \\
\text { masa yang akan } \\
\text { datang }\end{array}$ & $\begin{array}{l}\text { Fathia \& Arlini } \\
\text { (2012) }\end{array}$ \\
\hline Kegunaan $(\mathrm{X} 1)$ & $\begin{array}{l}\text { Kegunaan adalah } \\
\text { sejauh mana } \\
\text { seseorang meyakini } \\
\text { bahwa penggunaan } \\
\text { sistem informasi } \\
\text { tertentu akan } \\
\text { meningkatkan } \\
\text { kinerjanya }\end{array}$ & $\begin{array}{ll}\text { - } & \text { Efektivitas } \\
\text { - } & \text { Efesiensi } \\
\text { - } & \text { Minimalisir } \\
\text { - } & \text { Kesalahanan } \\
& \text { Kebangaan }\end{array}$ & $\begin{array}{l}\text { Utami \& Kusunawati } \\
\text { (2017) }\end{array}$ \\
\hline Keamanan (X2) & $\begin{array}{l}\text { Keamanan adalah } \\
\text { suatu kondisi dimana } \\
\text { tidak terdapat resiko } \\
\text { yang berarti dalam } \\
\text { melakukan suatu } \\
\text { tindakan }\end{array}$ & $\begin{array}{ll}\text { - } & \text { Berisiko } \\
\text { - } & \text { Kerugian } \\
\text { - } & \text { Ketidakpastian } \\
\text { - } & \text { Kemasalahan }\end{array}$ & $\begin{array}{l}\text { Chanchai } \\
\text { Phonthanukitithaworn } \\
\text { (2016) }\end{array}$ \\
\hline Akuntabilitas (X3) & $\begin{array}{l}\text { Akuntabilitas adalah } \\
\text { sebagai sebuah } \\
\text { kejelasan fungsi, } \\
\text { struktur, sistem dan } \\
\text { pertanggungjawaban } \\
\text { organisasi sehingga } \\
\text { pengelolaan } \\
\text { perusahaan terlaksana } \\
\text { secara efektif }\end{array}$ & $\begin{array}{ll}\text { - } & \text { Kepatuhan terhadap } \\
\text { prosedur } \\
\text { - } & \text { Pelayanan yang } \\
\text { cermat } \\
\text { - } \\
\text { Pelayanan yang } \\
\text { responsif } \\
\text { - } \begin{array}{l}\text { Pelayanan dengan } \\
\text { biaya murah }\end{array}\end{array}$ & Mahmudi (2013) \\
\hline Transparansi (X4) & $\begin{array}{l}\text { Transparansi adalah } \\
\text { suatu proses } \\
\text { keterbukaan dari para }\end{array}$ & $\begin{array}{ll}\text { - } & \text { Tersedia } \\
\text { pengumuman } \\
\text { kebijakan mengenai }\end{array}$ & $\begin{array}{l}\text { Nasim \& Romdhon } \\
\text { (2014) }\end{array}$ \\
\hline
\end{tabular}




pengelola manajemen,
utamanya manajemen
publik, untuk
membangun akses
dalam proses
pengelolaannya
sehingga arus
informasi keluar dan
masuk secara
berimbang

pengelola manajemen, utamanya manajemen publik, untuk membangun akses proses ( berimbang

\section{pendapatan,}

pengelolaan

keuangan dan aset.

- Tersedia laporan keuangan yang dapat diakses

- Tersedia laporan pertanggungjawaban yang tepat waktu.

- Tersedia sarana untuk suara dan usulan muzaki

- Tersedia sistem pemberian informasi

\section{HASIL DAN PEMBAHASAN}

Analisis data dan pengujian hipotesis dalam penelitian ini menggunakan metode Structural Equation Model - Parcial Least Square (SEM-PLS) dengan alat analisis data SmartPLS 3.0. SEMPLS meliputi uji outer model atau model pengukuran yang menunjukkan bagaimanan variabel manifest mempresentasi variabel laten yang diukur.

\section{Uji Outer Model}

Uji outer model atau model pengukuran di dalamnya terdapat uji validitas dan uji reliabilitas. Konstruk yang digunakan dalam penelitian ini sudah valid dan reliabel karena mempunyai nilai outer loading diatas 0,5 untuk uji validitas dan untuk uji reliabilitas setiap konstruk menunjukkan nilai cronbachs alpha dan composite reliability di atas 0,70 .

Tabel 2 Uji Validitas

\begin{tabular}{lcc}
\hline & Average Variance Extracted (AVE) & Keterangan \\
\hline Akuntabilitas & 0,912 & Valid \\
\hline Minat Menggunakan E-Zakat & 0,800 & Valid \\
\hline Kegunaan & 0,844 & Valid \\
\hline Risiko & 0,723 & Valid \\
\hline Transparansi & 0,748 & Valid \\
\hline
\end{tabular}

Sumber: Output PLS, 2020

Berdasarkan tabel di atas, maka nilai average variance extracted (AVE) menunjukan bahwa variabel laten Minat Menggunakan E-Zakat memiliki nilai AVE sebesar 0,800 sehingga dapat dikatakan valid karena nilai AVE >0,50. Kemudian pada variabel independen yakni Akuntabilitas (AK) sebesar 0,912, Kegunaan (KG) sebesar 0,844, Risiko (RS) sebesar 0,723, dan Transparansi (TP) sebesar 0,748. Maka nilai AVE variabel laten semuanya valid karena nilai AVE > 0,50.

Tabel 3 Cronbach's Alpha dan Composite Reliability

\begin{tabular}{lcc}
\hline & Cronbach's Alpha & Composite Reliability \\
\hline Akuntabilitas & 0,981 & 0,984 \\
\hline Minat Menggunakan E-Zakat & 0,963 & 0,970 \\
\hline Kegunaan & 0,950 & 0,960 \\
\hline Risiko & 0,926 & 0,939 \\
\hline Transparansi & 0,934 & 0,947 \\
\hline
\end{tabular}

Sumber: Output SmartPLS 3.0, 2020

Berdasarkan tabel di atas, hasil pengujian menunjukkan bahwa nilai Cronbachs alpha dan nilai Composite Reability seluruh konstruk berada pada nilai di atas 0,70. Hal tersebut menunjukkan bahwa sema item pernyataan yang digunakan untuk mengukur konstruk adalah reliabel. 


\section{Uji Inner Model atau Structural Model}

Dalam pengujian Inner Model (Model Struktural) dapat dilihat dari hubungan antar konstruk, nilai signifikan, dan R-square. Model structural dievaluasi dengan menggunakan Rsquare untuk konstruk endogen, Strone Geiser Q-Square untuk predictive revelance dan uji t serta signifikan dari koefisien parameter jalur struktural. Uji Inner Model dapat diketahui dengan melihat nilai skor R-Square. Dapat diketahui bahwa nilai R-Square variabel laten endogen (dependen) yaitu Minat Menggunakan E-Zakat sebesar 0,342. Dari nilai tersebut dapat diartikan bahwa nilai RSquare variabel dapat dikategorikan ke dalam kategori moderat karena berada di atas 0,33 menurut Chin. Sebesar 35\% konstruk variabel Minat Menggunakan E-Zakat dapat dijelakan dari model penelitian ini, sedangka ntuk sisanya yakni $65 \%$ dijelaskan oleh faktor lain diluar model penelitian. Penilaian model dapat melihat nilai R-square untuk variabel laten endogen. Berikut merupakan hasil pengujian $R$-square pada gambar 1

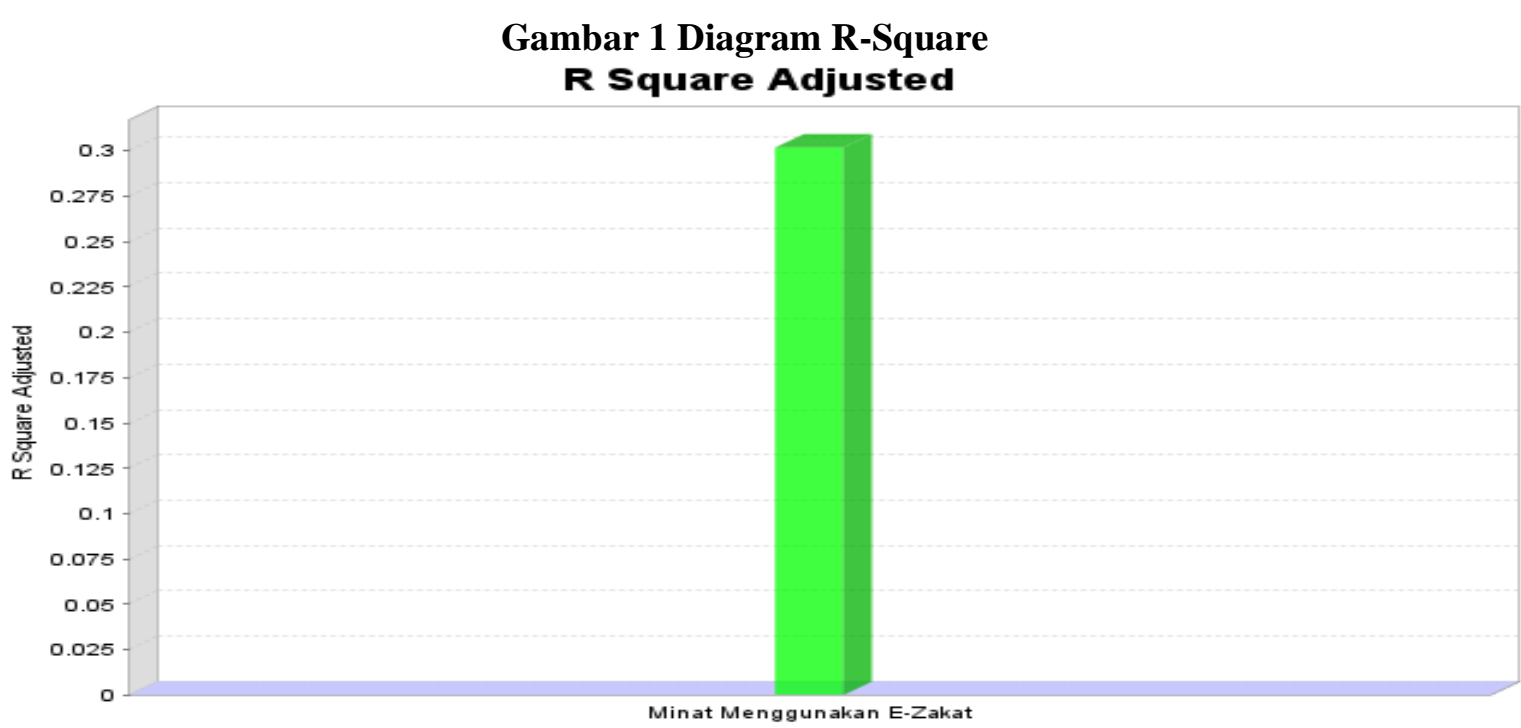

Sumber: Output Smart PLS 3.0, 2020

Tabel 4 Rekapitulasi Pengujian Hipotesis

\begin{tabular}{ccccccc}
\hline & $\begin{array}{c}\text { Original } \\
\text { Sample }\end{array}$ & $\begin{array}{c}\text { Sample } \\
\text { Mean } \\
(\mathbf{M})\end{array}$ & $\begin{array}{c}\text { Standart } \\
\text { Deviation } \\
(\text { STDEV })\end{array}$ & $\begin{array}{c}\text { T Statistics } \\
(|\mathbf{O} / \mathbf{S T D E V}|)\end{array}$ & $\begin{array}{c}\mathbf{P} \\
\text { Values }\end{array}$ & Keterangan \\
\hline $\begin{array}{l}\text { KG }-> \\
\text { MME }\end{array}$ & 0,340 & 0,340 & 0,099 & 3,423 & 0,000 & Diterima \\
\hline $\begin{array}{l}\text { RS }-> \\
\text { MME }\end{array}$ & $-0,231$ & $-0,239$ & 0,113 & 2,036 & 0,021 & Diterima \\
\hline $\begin{array}{l}\text { AK }-> \\
\text { MME }\end{array}$ & 0,127 & 0,124 & 0,085 & 1,492 & 0,068 & Ditolak \\
\hline $\begin{array}{l}\text { TP }-> \\
\text { MME }\end{array}$ & 0,197 & 0,211 & 0,095 & 2,065 & 0,020 & Diterima \\
\hline
\end{tabular}

Sumber: Output SmartPLS 3.0, 2020

Kegunaan E-Zakat berpengaruh Positif dan Signifikan terhadap Pengelolaan ZIS oleh LPZ di Kota Semarang

Berdasarkan hasil path coefficient, Hipotesis pertama yakni Kegunaan berpengaruh positif signifikan terhadap Minat Menggunakan E-Zakat diterima. Hasil penelitian juga konsisten dengan penelitian yang dilakukan oleh Teoh et al. (2013) dan Ozturk (2016) berpengaruh positif terhadap minat menggunakan e-money. Hubungan antar variabel menunjuk ke arah positif, hal ini berarti responden memiliki keyakinan bahwa Kegunanan atau manfaat yang diperoleh dari E-Zakat mampu mendorong dan meningkatkan minat muzaki/donatur untuk membayar ZIS secara digital melalui E-Zakat. 
Alasan diterima hipotesis juga sesuai dengan teori Technology Acceptance Model (TAM) yaitu sebuah teori yang ditemukan oleh oleh Davis (1989) sebagai pengembangan teori yang ada sebelumnya yaitu Theory of Reasoned Action oleh Azjen dan Fisbein (1980). Teori TAM ini digunakan untuk mengetahui faktor-faktor yang mempengaruhi suatu individu dalam menggunakan teknologi dalam berbagai aktivitasnya. Model dari teori TAM ini memberikan gambaran bahwa faktor seseorang menggunakan teknologi dalam aktivitasnya dipengaruhi oleh faktor perceived usefullnes (manfaat) dan perceived ease of use (kemudahan penggunaan). Kedua faktor tersebut telah teruji secara empiris memiliki determinan dan validitas yang tinggi sehingga menjadi penyebab seseorang menggunakan teknologi dalam aktivitasnya. Teori TAM ini meyakini bahwa dengan penggunaan teknologi akan mampu mempermudah dan meningkatkan kinerja pemakainya baik individu maupun lembaga.

Perceived usefullnes (manfaat) merupakan sebuah keyakinan seseorang akan mendapatkan atau tidak mendapatkan manfaat keuntungan sebagai akibat dari penggunaan suatu teknologi. Apabila penggunaan teknologi tersebut dapat meningkatkan kinerja suatu individu atau organisasi, maka akan mempengaruhi perilaku individu atau organisasi untuk terus memanfaatkan teknologi dalam menunjang aktivitasnya. Dengan demikian, muzaki/donatur akan semakin tertarik untuk terus menggunakan layanan E-Zakat dalam membayar ZIS.

\section{Risiko Berpengaruh Negatif dan Signifikan terhadap Pengelolaan ZIS oleh LPZ di Kota Semarang}

Berdasarkan hasil path coefficient, hipotesis kedua yakni Risiko berpengaruh negatif terhadap Efisiensi OPZ diterima. Hasil pengujian menunjukkan ke arah negatif yang berarti bahwa semakin tinggi resiko, maka akan semakin rendah intensitas muzaki untuk membayar ZIS melalui E-Zakat dan sebaliknya jika semakin rendah risiko, maka akan semakin meningkatkan intensitas muzaki untuk menggunakan layanan E-Zakat dalam membayar ZIS. Hasil penelitian ini konsisten dengan penelitian yang dilakukan oleh Fong (2016), dan (Ozturk 2016)bahwa Risiko berpengaruh negatif terhadap minat menggunakan OVO Mobile Payment.

Alasan diterima hipotesis juga sesuai dengan teori Innovation Diffusion Theory (IDT). Hubungan teori IDT dalam penelitian ini karena dalam IDT menjelaskan bahwa terdapat 5 kelompok adopter, salah satunya adalah early majority yaitu kelompok orang-orang yang mengadopsi teknologi hanya ketika teknologi tersebut bermanfaat dan telah banyak diapdopsi pengguna lain. Dari sisi kesiapan menanggung risiko kelompok ini lebih berhati-hati. Maka dari itu persepsi risiko dapat mempengaruhi tingkat penggunaan teknologi baru seperti E-Zakat. Semakin tinggi tingkat risiko pada $E$-Zakat maka semakin rendah minat masyarakat untuk menggunakan $E$ Zakat.

\section{Akuntabilitas Berpengaruh Positif dan Siginifikan terhadap Pengelolaan ZIS oleh LPZ di Kota Semarang ditolak}

Berdasarkan hasil path coefficient, T-Statistik menunjukkan angka 0,870 dan T-table menunjukkan angka 0,105. Hipotesis ketiga yakni Akuntabilitas berpengaruh positif terhadap Minat Menggunakan E-Zakat ditolak karena nilai T-Statistik < 1,96 yang berarti bahwa akuntabilitas tidak memiliki pengaruh yang signifikan terhadap Minat Menggunakan E-Zakat. Hasil ini sejalan dengan penelitian yang dilakukan oleh Novilia \& Jayanto (2018) dan Yuliafitri and Khoiriyah (2016) bahwa Akuntabilitas juga tidak memiliki pengaruh terhadap minat muzakki dalam membayar Zakat.

Hasil analisis statistik responden menunjukkan bahwa 93\% responden menilai E-Zakat memiliki tingkatan akuntabilitas yang tinggi sedangkan $7 \%$ responden lainnya menilai E-Zakat memiliki akuntabilitas yang rendah. Meskipun 93\% rsponden memberi akuntabilitas yang tinggi, namun tidak cukup signifikan untuk menjadi faktor yang mempengaruhi pengelolaan Zakat. Hasil ini dimungkinkan karena dalam E-Zakat, preferensi muzaki dalam hal membayar ZIS secara digital terfokuskan pada variabel-variabel lainnya yaitu kegunaan, risiko, dan transparansi yang ada pada E-Zakat. Meskipun Akuntabilitas merupakan sesuatu yang positif dan patut dipertimbangkan, namun tidak cukup kuat untuk dipertimbangkan oleh muzaki/donatur sehingga akuntabilitas tidak berpengaruh secara signifikan. 


\section{Tranparansi Berpengaruh Positif dan Signifikan terhadap Pengelolaan ZIS oleh LPZ di kota Semarang}

Berdasarkan hasil path coefficient, T-Statistik menunjukkan angka 2,029 dan T-table menunjukkan angka 0,197. Dapat disimpulkan bahwa hipotesis keempat yakni Transparansi berpengaruh positif terhadap Minat Menggunakan E-Zakat diterima karena T-Statistik >1,96. Hasil penelitian ini sejalan dengan hasil penelitian yang dilakukan oleh Yuliafitri \& Khoiriyah (2016) bahwa Transparansi berpengaruh positif terhadap loyalitas muzaki, Pangestu \& Jayanto (2017) bahwa Transparansi mempunyai pengaruh positif terhadap motivasi membayar zakat, dan Novilia \& Jayanto (2018) bahwa variabel transparansi berpengaruh positif dan signifikan terhadap minat muzaki membayar zakat.

Good Corporate Governance (GCG) ini dapat dijadikan sebagai landasan teori dalam penelitian ini karena teori ini akan menunjukkan bahwa transparansi menjadi sebuah keharusan dalam mewujudkan pertanggungjawaban yang menyeluruh kepada seluruh stakeholder lembaga atau entitas. Dalam praktiknya pada OPZ, transaparansi lembaga menjadi hal yang penting bagi muzaki mempercayakan zakatnya. Muzaki tidak akan ragu untuk menyalurkan zakatnya kepada OPZ terkait karena OPZ telah menunjukkan pertanggungjawabannya melalui akuntabilitas dan transparansi OPZ.

\section{KESIMPULAN}

Tujuan dalam penelitian ini adalah untuk meneliti faktor-faktor apa saja yang mempengaruhi minta menggunakan E-Zakat dalam Membayar Zakat, Infaq, dan Sedekah (ZIS). Jumlah responden yang dibutuhkan dalam penelitian ini sebesar 70 responden menggunakan metode quota sampling yang merupakan pegawai yang bekerja pada Lembaga Pengelola Zakat berskala provinsi dan nasional yang telah menggunaka layanan E-Zakat dalam pembayaran ZIS. Variabel yang digunakan dalam penelitian ini adalah Kegunaan, Kemudahan, Risiko, Akuntabilitas, dan Transparansi. Analisis yang digunakan adalah SEM (Structural Equation Modeling) dengan menggunakan SmartPLS 3.0.

Berdasarkan hasil penelitian, variabel Kegunaan dan Transparansi memiliki pengaruh positif dan signifikan terhadap Minat Menggunakan E-Zakat. Risiko berpengaruh secara negatif dan signifikan terhadap Minat Menggunakan E-Zakat. Dapat disimpulkan bahwa Minat Menggunakan E-Zakat dalam membayar Zakat, Infak, dan Sedekah ZIS) dipengaruhi oleh variabel Kegunaan, Risiko, dan Transparansi dalam layanan E-zakat sedangkan Akuntabilitas tidak cukup signifikan berpengaruh terhadap Pengelolaan ZIS oleh LPZ.

Keterbatasan dalam penelitian ini adalah tidak terlalu luas hanya berada dalam cakupan Kota Semarang. Selain itu, peneliti selanjutnya dapat menghadirkan variabel lainnya atau memodifikasi model penelitian yang baru karena dalam penelitian ini nilai R-square hanya 0,342 yang artinya sebesar 65\% Pengelolaan ZIS oleh LPZ dipengaruhi oleh faktor-faktor di luar model penelitian ini.

\section{DAFTAR PUSTAKA}

Emirzon, and Joni. 2007. Prinsip-Prinsip Good Corporate Governance Paradigma Baru Dalam Praktik Bisnis Indonesia. Yogyakarta: Genta Press.

Fathia, and Arlini. 2012. "Faktor Determinan Minat Individu Menggunakan Kartu Kredit." Jurnal Manajemen Pemasaran. Universitas Brawijaya Malang.

Fong, Chanchai Phonthanukitithaworn Carmine Sellitto Michelle W. L. 2016. "Asia-Pacific Journal of Business." Asia-Pacific Journal of Business Administration 8(1).

Maulidiyah, Nikmahtul, and Darno. 2019. "Pengaruh Transparansi Dan Akuntabilitas Laporan Keuangan Terhadap Kepercayaan Donatur Di Yayasan Sosial Keagamaan.” Jurnal Akuntansi Terapan 1:8.

Novilia, Puja, and Prabowo Yudo Jayanto. 2018. "Pengaruh Motivasi, Kepemimpinan, Komitmen Organisasi, SIA, Transparansi Dan Akuntabilitas Terhadap Kinerja Karyawan Perbankan Syariah." Universitas Negeri Semarang, Semarang.

Ozturk, Ahmet Bulent. 2016. "Customer Acceptance of Cashless Payment Systems in The Hospitality Industry." International Journal of Contemporary Hospitality Management 
28(2):327-45.

Pangestu, Itaq, and Prabowo Yudo Jayanto. 2017. "Analysis in Factors Affecting Muzakki Motivation to Pay Zakat in Semarang City." 6(1):94-103.

Rahayu, Septi Budi, Sri Widodo, and Enita Binawati. 2018. "Pengaruh Akuntabilitas Dan Transparansi Lembaga Zakat Terhadap Tingkat Kepercayaan Muzakki." Journal of Business and Information System 1(2):103-14.

Ramadhan, Adi Firman, Andrian Budi Prasetyo, and Lala Irviana. 2016. "Persepsi Mahasiswa Dalam Menggunakan E-Money." Jurnal Dinamika Ekonomi \& Bisnis 13:1-15.

Surya, Indra. 2006. Penerapan Good Corporate Governance: Mengesampingkan Hak-Hak Istimewa Demi Kelangsungan Usaha. Jakarta: Kencana.

Teoh, Wendy Ming-Yen, Siong Choy Chong, Binshan Lin, and Jiat Wei Chua. 2013. "Factors Affecting Consumers' Perception of Electronic Payment: An Empirical Analysis." The International Journal of Logistics Management 20(1):97-123.

Utami, Sulistyo Seti, and Berlianingsih Kusumawati. 2017. "Faktor-Faktor Yang Memengaruhi Minat Penggunaan E-Money (Studi Pada Mahasiswa STIE Ahmad Dahlan Jakarta)." Jurnal Balance XIV(2).

Wahyudin, Agus. 2015. Metodologi Penelitian Bisnis Dan Pendidikan. 1st ed. Semarang: UNNES Pers.

Yuliafitri, Indri, and Asma Khoiriyah. 2016. "Pengaruh Kepuasan Muzakki, Transparansi Dan Akuntabilitas Pada Lembaga Amil Zakat Terhadap Loyalitas Muzakki." Islamiconomic: Jurnal Ekonomi Islam 7:205. 